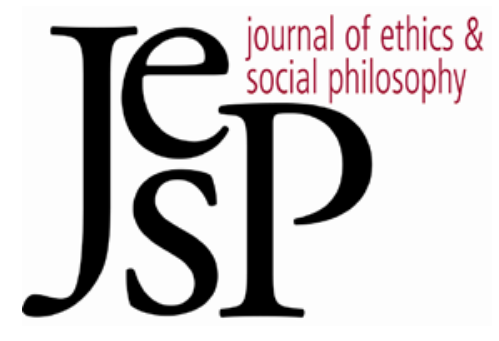

\title{
Moral Explanations, Thick and Thin
}

\author{
By Brendan Cline
}

JOURNAL OF ETHICS \&SOCIAL PHILOSOPHY

Vol. 9, No. 2 | SePtember 2015 URL: WWW.JESP.ORG COPYRIGHT (C) BRENDAN CLINE 2015 


\title{
Moral Explanations, Thick and Thin
}

\author{
Brendan Cline
}

$S^{\infty}$

OME HAVE DOUBTED that, when we appropriately sift through our catalog of what there is, moral properties will have what it takes to remain (e.g., Mackie 1977; Blackburn 1984; Gibbard 1990; Joyce 2001). In one well-known iteration of this challenge, Gilbert Harman (1977) questions the explanatory utility of moral properties. It seems, he suggested, that we may be able to slim down our ontological commitments without explanatory loss by doing away with moral properties.

This challenge has given rise to a compelling form of nonreductive moral naturalism - sometimes called Cornell realism. Cornell realists accept Harman's challenge and respond by arguing that moral properties have earned a place in our ontology in virtue of the indispensable role they play in the best explanation of various phenomena (Sturgeon 1988, 2006; Brink 1989; SayreMcCord 1988). ${ }^{1}$

This inventive line of response has considerable appeal. However, its viability depends importantly on a particular thesis about the semantics of thick concepts. Unfortunately for Cornell realists, Väyrynen's (2013) Pragmatic View of thick concepts enjoys considerable support and is hostile to the strongest moral explanations currently on offer. If concepts like COURAGEOUS, KIND, LEWD, OPPRESSIVE and so on are not inherently evaluative, then the most plausible moral explanations Cornell realists have offered cannot do the work they are meant to. Thus, in the absence of strong reasons to reject the Pragmatic View, Cornell realism is significantly weakened. In particular, I will argue, if Väyrynen's Pragmatic View of thick concepts is correct, then Cornell realists must either endorse reductive naturalism in order to retain their most credible moral explanations, or they must restrict moral explanations to their least plausible examples - namely those that employ thin concepts such as GOOD and RIGHT. Neither choice bodes well for their view.

\section{Ontological Rights for Moral Properties?}

In his original presentation of the explanatory challenge, Harman (1977) asks us to contrast two cases. In the first, Jane sees Albert pouring gasoline on a cat and then lighting it on fire for fun. This observation leads Jane to noninferentially form the belief that Albert has done something wrong. ${ }^{2}$ In the se-

\footnotetext{
${ }^{1}$ Richard Boyd is often characterized as a Cornell realist. I avoid his work here since his arguments do not center on the sorts of moral explanations that I will be criticizing, but see e.g., Boyd 1988, 2003a, 2003b.

2 Jane and Albert actually do not enter the scene until Harman (1986), but I use them here for ease of exposition.
} 
cond case, a physicist observes a vapor trail in a cloud chamber and from this observation noninferentially forms the belief that a proton has gone by. According to Harman, it appears that, while we need to appeal to protons in order to explain the observation of the physicist, we need not appeal to the wrongness of igniting cats in order to explain Jane's observation about Albert's action. It seems that facts about Jane's ethical sensibility and her beliefs about what Albert was doing are all that is required to explain her observation. Indeed, given those facts, it looks like Jane would make the same judgment whether or not Albert's act was wrong. So perhaps our moral judgments do not constitute evidence for moral facts.

Sturgeon (1988) objects that this argument relies on an illicit assumption. Only one who already accepts moral skepticism will find Harman's contrast convincing, because the dissimilarity between the two cases can only be motivated by assuming that the physicist's theory is roughly true and that Jane's moral views are roughly false. For, if the physicist's theory of particles is mistaken, then we would not need to appeal to protons in order to account for her observation (cf. Brink 1989: 185-86). Thus, in order to formulate a challenge that is convincing to the realist, Harman would need to show that moral facts are explanatorily irrelevant even if commonsense moral beliefs are roughly true. And, Sturgeon maintains, this simply is not plausible. If Jane's moral views are roughly true, then lighting cats on fire for fun is wrong. Since the moral supervenes on the natural, Albert would have needed to do something different to the cat (e.g., pour water on it to clean its fur) in order for his act not to be wrong. And if Jane observed that happening, then she would not have judged that what Albert did was wrong. So it is not the case that she would have judged his act wrong regardless of whether or not it was wrong. And, in general, it seems that our moral judgments counterfactually depend on the moral facts in this way, which suggests that such facts are indeed relevant to the explanation of our judgments. ${ }^{3}$

Now, it is important to remember that Harman himself is not a moral skeptic. ${ }^{4} \mathrm{He}$ answers his explanatory challenge by motivating a version of reductive naturalism according to which moral properties reduce to certain kinds of descriptive properties (e.g., Harman 1977, ch. 11). Thus he thinks that moral properties in fact do figure in our best explanations, because they are identical to certain explanatorily relevant properties that initially appear less problematic. Sturgeon and the other Cornell realists, however, wish to maintain a version of naturalism according to which moral properties are explanatorily relevant and constituted by nonmoral properties, but cannot be reduced to or identified with nonmoral properties.

\footnotetext{
3 In support, Sturgeon (1988: 245) proposes the following counterfactual test: " $\mathrm{I}] \mathrm{f}$ a particular assumption is completely irrelevant to the explanation of a certain fact, then the fact would have obtained, and we could have explained it just as well, even if the assumption had been false." It is known that this test has problems, but we need not sort them out here.

${ }_{4}^{4}$ Although he is a moral relativist, he denies that this amounts to skepticism.
} 
A central point of contention between these positions revolves around the distinction between descriptive and evaluative vocabulary. What is the difference between these vocabularies? There is no straightforward answer and I do not intend to propose an analysis of evaluative language here, but it will be useful to have the following criterion from Väyrynen (2013: 55) in the background:

[A] thick term or a concept $T$ is inherently evaluative in meaning if literal uses of sentences of the form $x$ is $T$ in normal contexts entail, as a conceptual matter or in virtue of a semantic rule, that $x$ is good or bad (depending on $T$ ) in a certain way where "a semantic rule" covers also such further semantic properties as conventional implicature and semantic presupposition.

Reductive naturalists claim that the properties ascribed by evaluative predicates - call them evaluative properties - are identical to some of the properties ascribed by descriptive predicates - call them descriptive properties. ${ }^{5}$ Cornell realists are characterized by the denial of this claim: According to them, the properties ascribed by our evaluative vocabulary are not reducible (analytically or synthetically) to the properties ascribed by some subset of our descriptive vocabulary. ${ }^{6}$ Thus, the present debate is appropriately conceived of as centering on explanations that employ evaluative terms and concepts. The key question is whether or not the properties ascribed by those kinds of terms and concepts can be reduced to the properties ascribed by descriptive terms and concepts. ${ }^{7}$

In the sense relevant here, reductions identify one kind of thing with another kind of thing. Such an identification is appropriate when it turns out that one and the same thing (or property) is denoted by two different predicates, e.g., water and $\mathrm{H}_{2} \mathrm{O}$. However sometimes it is inappropriate to pursue reductive identifications, such as reducing types of psychological states to types of neurophysiological states (Fodor 1974). For physicalists, instances of e.g., pain are (typically) identical to some instance of a neurophysiological state. However, the fact that the same psychological state can be realized in a

${ }^{5}$ See e.g., Jackson and Pettit (1996: 83), Jackson (1998: 123), Railton (1986: 205), Miller (2013: 143-44).

${ }^{6}$ For example, in resisting reductive naturalism, Sayre-McCord argues that certain moral explanations "rely on moral concepts that identify characteristics common to people, actions and institutions that are uncapturable with finer-grained or differently structured categories" (1988: 276). Along similar lines, Sturgeon contrasts his preferred version of naturalism with the reductive naturalist's view that "we either are or will be able to say, in entirely nonmoral terms, exactly which natural properties moral terms refer to" in virtue of possessing naturalistic reductive definitions (1988: 243). Cf. Brink (1989: 9): "A nonreductive form of ethical naturalism claims that moral facts and properties are constituted by, and so supervene upon ... natural and social scientific facts and properties even if moral terms are not definable by natural terms." See also Brink (1989: 156-59) and Jackson (1998: 144).

7 I will follow Väyrynen (2013: 44-55) in taking the content of our terms to be related to the content of our concepts in such a way that findings about the semantics of our terms constrain the semantics of our concepts. 
variety of different ways makes it improper to reduce the type of psychological state ascribed by "pain" to some particular type of state ascribable using terms available in the vocabulary of neurophysiology. Pain is a natural kind about which interesting counterfactual-supporting generalizations can be made. However, its various instances are not homogeneous at the level of neurophysiology and thus cannot be identified with the natural kinds posited by neurophysiology, despite the fact that such states supervene on and are constituted by neurophysiological states.

In what follows, I want to concede a lot of ground to the Cornell realists for the sake of argument. So while it may sound question begging against e.g., compositional nihilists and psychological reductionists, I will accept the antireductionist attitude just outlined. Toward that end, I hope I will be permitted here to use the label reductive mistakes for cases in which a particular view entails a reductive error, such as type-type reductionism about psychological and neurophysiological states. In contrast, I will use the label objectionable reductionism for views that imply that everything - from DNA to beliefs to water - reduces to (or can be eliminated in favor of) the fundamental constituents of the universe (e.g., particles, strings or whatever). With this in place, we return to the exchange between Harman and the Cornell realists.

\section{Cornell Realism and Moral Explanations}

In reply to Harman's challenge of explanatory impotence, Cornell realists have tried to motivate nonreductive naturalism about moral properties by arguing that we are familiar with a range of robust, irreducibly moral explanations of various phenomena. Here are some putative examples:

(1) Honesty engenders trust.

(2) Kindness encourages friendship.

(3) Mother Teresa's goodness won her a Nobel Prize.

(4) People are starving unnecessarily because of the selfishness of others.

(5) Racial oppression caused political instability and social protest in apartheid South Africa.

(6) Hitler instigated and oversaw the deaths of millions of persons because he was morally depraved.

(7) Woodworth spent his time and energy arranging his own conveniences rather than organizing an effective search for the missing people because he was no damn good. 8

These moral explanations, it is claimed, appeal to irreducible moral properties and thus motivate a nonreductive view about moral properties that is analogous to the case for nonreductionism about psychological states. The multiple realizability of moral properties like kindness, oppression and goodness

8 (1)-(4) come from Sayre-McCord (1988: 275-76); (5) comes from Brink (1989: 187); (6) and (7) come from Sturgeon $(1988: 234,249)$. All three authors explicitly draw analogies with the case for nonreductionism about psychological states. 
suggests that they cannot be reduced to descriptive properties. Thus, we should think of them as having the same ontological status as psychological states, DNA and other irreducible entities posited by the special sciences.

Critics of this view have tended to deny the truth of the explanations offered in (1)-(7) (but see Sinclair 2011). For example, Leiter (2001) denies that honesty's engendering trust is a better explanation than the perception of honesty's engendering trust (cf. Quinn 1986). He also suggests (2001: 94) that (6) is nothing more than a restatement of what needs to be explained. Along similar lines, Blackburn (1993: 204-05) and Sinhababu (unpublished manuscript) argue that psychological explanations appealing to our attitudes toward social arrangements and others' behavior tend to be better than the competing moral explanations.

These sorts of replies can seem somewhat strained, bordering on reductive mistakes. For example, why did people think there was racial oppression in apartheid South Africa? Plausibly, because there was racial oppression in apartheid South Africa (cf. Brink 1989: 187-89; Majors 2003).

Other attempts to deny the truth of these explanatory claims have led authors close to endorsing objectionable reductionism. For example, Thomson (1996) argues that evaluative properties like rudeness are epiphenomenal: All the causal-explanatory work being done in appeals to rudeness is accomplished by the subvening descriptive properties on which rudeness supervenes (cf. Blackburn 1993: 205-06). Along similar lines, Miller (2013, ch. 8) claims that moral properties appear to figure in some of our best explanations only due to our epistemic limitations. If we did not suffer from such limitations, then we could dispense with the higher-level properties and would only require appeals to the microstructural facts about these cases.

As Sturgeon $(1986,1998,2006)$ points out, the principles behind these argumentative strategies would require that we also dispense with unobjectionable entities such as psychological states and DNA (see also Majors 2003, 2007; Nelson 2006; cf. Miller 2009). For example, one might analogously argue that all of the causal-explanatory work being done in appeals to psychological states is really being done by the subvening physical states on which psychological states supervene. But it seems that at least Thomson does not desire to jettison psychological states and the like from her ontology. Something must be going wrong.

In what follows, I present an objection to the moral explanations of Cornell realists that does not suffer from the problem of objectionable reductionism. I will even allow that kindness really does encourage friendship, and oppression really does cause protest and political instability. Furthermore, I will grant Sturgeon the assumption that our considered moral judgments are roughly true: Ceteris paribus, torture is wrong, charity is laudable and kindness is good. Even with these concessions, we can spot a serious weakness in these arguments by paying careful attention to recent work on thick ethical concepts - to which we now turn. 


\section{The Pragmatic View of Thick Concepts}

The distinction between thick and thin ethical concepts can be sketched as follows. Thin concepts - which include GOOD, BAD, RIGHT, WRONG - semantically convey evaluations of actions, characters and states of affairs, but do not contain any further descriptive information. As Elstein and Hurka explain (2009: 516):

The mark of a thin concept like "right" is that it says nothing about what other properties an item falling under it has ... [W] hile the claim " $\mathrm{x}$ is right" says or implies that $\mathrm{x}$ has some right-making properties, it says nothing about what in particular they are. ${ }^{9}$

In contrast, thick terms and concepts are often characterized as somehow holding together description and evaluation (Williams 1985, chs. 7-8). Paradigmatic examples of thick concepts include COURAGIOUS, CRUEL, BRUTAL, CALLOUS, KIND, HONEST, LEWD and OPPRESSIVE. The characteristic feature of these concepts is that they seem to simultaneously describe and evaluate. For example, someone who is callous is not just bad, but bad in a certain way (perhaps bad in virtue of being indifferent to the well-being of others).

Accounts of thick concepts have tended to cluster into two categories, which we can follow Väyrynen (2013: 11-15) in calling separabilism and inseparabilism. Separabilists claim that it is possible - at least in principle - to isolate the descriptive from the evaluative components of these concepts (Elstein and Hurka 2009; Miller 2013: 240-52). Inseparabilist accounts maintain that the evaluative and descriptive aspects of thick concepts cannot be disentangled from one another (Williams 1985; Kirchin 2010; Roberts 2011). Despite their disagreements, both separabilists and inseparabilists tend to endorse the following thesis:

Inherently Evaluative: The meanings of thick terms and concepts somehow or other contain evaluation. ${ }^{10}$

This would be true if the evaluations were part of the literal semantic content of thick terms and concepts, or if the evaluations were something like semantic presuppositions or conventional implicatures (cf. Väyrynen's characterization of evaluative predicates in $\int 1$ ). The question for those who endorse Inherently Evaluative is how to best analyze the relationship between the evaluative and descriptive semantic content of these terms and concepts.

However, as Väyrynen (2013) observes, this thesis has received limited critical scrutiny (but see Blackburn 1992; Kyle 2013). In fact, he argues, if we

\footnotetext{
${ }^{9}$ Korsgaard (1996: 71) offers a nice characterization of thin concepts along similar lines: "Pure in their normativity, they are like those little gold stars you can stick on anything." 10 Väyrynen (2013: 9).
} 
apply standard techniques from linguistics and the philosophy of language for assessing the semantic content of our terms, it turns out that there are very good reasons for rejecting Inherently Evaluative. Consequently, Väyrynen advocates a Pragmatic View of thick terms and concepts according to which the evaluative information conveyed by thick terms arises from pragmatic conversational mechanisms that rely on the shared evaluative backgrounds of speakers within a linguistic community.

In what follows, I will be relying heavily on this account. The claim will be that the Pragmatic View deflates the appeal of Cornell realism by disarming the most persuasive moral explanations that have been proposed. In order to avoid this, Cornell realists need to provide a plausible alternative to Väyrynen's Pragmatic View. ${ }^{11}$ Since there is not room for a full defense of Väyrynen's (admittedly controversial) account here, I will simply assume that it is roughly true and explore its consequences. While the merits of the Pragmatic View must be assessed on the merits of the arguments in Väyrynen's book, I will briefly motivate it before returning to the moral explanations offered by the Cornell realists (see also Väyrynen 2009, 2012; Bedke 2014).

One of Väyrynen's central arguments involves appealing to the method of assessing the semantic content of an utterance by observing the way its implications project. Here is the characterization of projection he uses: "An implication projects if and only if it survives as an utterance implication when the expression that triggers the implication occurs under the syntactic scope of an entailment-canceling operator" (Simons et al. 2010: 309; see Väyrynen 2013: 60). The idea is that, if certain implications of an utterance project, then they are not conceptual or semantic entailments of the utterance. To illustrate, Väyrynen uses the following example (2013: 60):

(8) Anna regrets drinking instant coffee this morning.

a. Anna has negative feelings about drinking instant coffee this morning.

b. Anna drank instant coffee this morning.

Here, both (8a) and (8b) are implications of (8).

Now watch what happens when the expression in (8) is embedded within the scope of various entailment-canceling operators (e.g., questions, negation, possibility modals, antecedents of conditionals):

(9) a. Does Anna regret drinking instant coffee this morning?

b. Anna doesn't regret drinking instant coffee this morning.

c. Anna might regret drinking instant coffee this morning.

d. If Anna regrets drinking instant coffee this morning, then my dislike of instant coffee is vindicated.

${ }^{11}$ Ken Shockley has suggested to me that perhaps this sort of argument might be able to go through even if the Pragmatic View is false but separabilism is true. I do not pursue that approach here, but see Quinn (1986: 534-35). 
As Väyrynen points out, the implication in (8b) is still present in (9a)-(9d), all of which have (8) embedded within the scope of entailment-canceling operators. However, notice that the implication in (8a) does not remain in any of these situations. The basic idea is that, whereas (8b) is not a conceptual or semantic entailment of (8), (8a) is. If you cancel the entailments of (8) you cancel (8a), but (8b) still sticks around. A plausible explanation is that (8b) is neither part of the literal meaning of (8) nor entailed by it, but rather a presupposition behind the utterance in (8).12

Now, what if we apply this test to thick terms and concepts? Consider the term "lewd." Väyrynen (2013: 62) asks us to imagine a conversation between two individuals who sometimes describe things as lewd and believe that those things are bad in a certain way in virtue of their lewdness. These two know that they both share this attitude toward lewd acts, and that people typically only use the word "lewd" when they associate negative evaluations with acts that transgress conventional boundaries on sexual display. Suppose that they are discussing a show that will be in town next week and the first utters (10), to which the second replies with (11):

(10) Madonna's stage show is lewd.

(11) Nah, Madonna's show isn't lewd.

In this context, Väyrynen points out, we naturally hear (11) as denying that there is sufficient transgressive sexual display for the show to be labeled as lewd. If asked to elaborate, the second person might say:

(12) Madonna's show is sexually insinuating alright, but it's not lewd because no private parts are exposed.

However, notice that (11) does not seem to be denying either of the following:

(13) Overt displays of sexuality that transgress conventional boundaries are bad in a certain way.

(14) If Madonna's show involves overt display of sexuality that transgresses conventional boundaries, then it is bad in a certain way.

It seems natural to suppose that the utterer of (11) still endorses (13) and (14). The fact that these evaluations associated with "lewd" are not canceled when (10) gets embedded in entailment-canceling contexts (such as in (11)) suggests that they project. And this, Väyrynen argues, provides strong reasons for thinking that the evaluations in (13) and (14) are not part of the central point of using the word "lewd," but rather are backgrounded features of utterances that employ it.

12 While projection is often used to test for presupposition, there are other kinds of utterance implications that project as well (see Simons et al. 2010). This will be important below. 
On this interpretation, the evaluations are not-at-issue with respect to the question under discussion when speakers describe things using "lewd" and other thick terms, since this is what projection seems to test for (Simons et al. 2010). Furthermore, the fact that these evaluations are not semantic entailments of utterances containing "lewd" counts against the view that they are part of the meaning of "lewd." However, several possible accounts could satisfy Inherently Evaluative, and not all of them treat the evaluative content of thick concepts as semantic entailments. It is possible to defend Inherently Evaluative by treating the evaluations as conventional implicatures or semantic presuppositions $(\sqrt{2})$. Thus the projection argument only partially supports Väyrynen's Pragmatic View.

Another argumentative thread that animates Väyrynen's approach is the observation that it is not incoherent to challenge the evaluations that are usually associated with many thick terms and concepts. For example, it is possible to wonder whether selfishness is bad, and Gordon Gekko is plausibly regarded as exhibiting a normative failing, rather than conceptual confusion, when he asserts that greed is good. This is indicative of the fact that the evaluations commonly associated with thick terms appear to be defeasible in various contexts. For example, Väyrynen (2013: 70) suggests that someone who objects to the evaluations in (13) and (14) associated with "lewd" might reply to the speaker in (10) by saying:

(15) Whether or not Madonna's show is lewd, it's not bad in any way distinctive of explicit sexual display.

These observations are not what one would expect if the evaluations associated with thick terms and concepts were part of their meaning. And indeed, this defeasibility of the evaluative implications associated with thick terms tells against interpreting them as some other semantic property, such as conventional implicatures or semantic presuppositions (Väyrynen 2013: 103-05, 109-16). For example, contrast (15) with the following:

(16) \#Whether or not Anna drank instant coffee this morning, we can truthfully say that Anna regrets drinking instant coffee this morning. ${ }^{13}$

Because the implication in (8b) is plausibly regarded as a semantic presupposition of (8), it cannot be felicitously suspended in the way that (15) suspends the evaluative implications of (10).

Väyrynen argues that by reviewing considerations such as these, we can see that the most plausible account of thick terms and concepts is that the evaluations they are used to convey are not part of their semantic meaning, but instead arise pragmatically from the evaluative backgrounds shared by speakers in a linguistic community. The idea is that those who are interested in classifying people using "chaste" or "unchaste," for example, are typically

13 Väyrynen 2013: 115. 
embedded within a culture in which chastity is held to be evaluatively significant. When they engage in such categorization, they typically do so in the context of communicating with others who share a similar evaluative background. Mutual awareness of this explains why the evaluations associated with thick terms and concepts are typically not-at-issue in utterances containing thick terms (Väyrynen 2013: 128ff). ${ }^{14}$

To illustrate, consider an example that does not contain a thick evaluative term:

(17) Did you hear about Jim? He feeds his kids GMOs every day.

The assertion in the second sentence of (17) is true just in case Jim feeds his kids GMOs every day. However, if this is said by someone who is known to be suspicious of GMOs, and is said to someone whom the speaker knows to be suspicious of GMOs, the speaker is able to convey a negative appraisal of Jim's behavior through the utterance. This appraisal is not part of the truthconditions of the utterance or the meaning of "GMOs," but rather arises from mutual knowledge of these shared evaluative attitudes toward GMOs. According to the Pragmatic View, the evaluations conveyed by thick terms arise pragmatically in a similar manner.

I wish to highlight two features of this account. First, the Pragmatic View is meant to apply to most paradigmatic terms and concepts that can be classified as thick. Väyrynen (2013: 150-55) acknowledges that it is unclear how to treat pejoratives, but it is also unclear that they will have much significance in the present context. He also grants that locutions such as "a good $x$ " may be thick and inherently evaluative in some way. This class may be more significant, but for simplicity I will temporarily assume that the Pragmatic View applies to all thick terms and concepts, returning to "a good $x$ " later. The second thing to note is this: The fact that the evaluations conveyed by thick terms are not part of their semantic meaning leads to the view that these terms may not have an empty extension even if the evaluations they are typically used to convey are not true. For example, if Gibbard (1992) is correct that things are not bad in any way in virtue of involving sexual displays that transgress conventional boundaries, such acts may still be lewd nevertheless. Since the evaluations that speakers typically associate with thick terms are not part of their meaning or truth-conditions, incorrect evaluations do not render thick terms empty.

With the Pragmatic View in place, we now return to moral explanations.

${ }_{14}$ This account also explains why, even if the evaluations are not part of the literal meaning of thick terms, it can still be misleading for a speaker to employ certain words in certain contexts, since this can be taken as a signal that the speaker endorses the relevant evaluative outlook. For example, imagine someone who is evaluatively indifferent toward observing Judaic dietary law asking their waiter whether their meal is kosher. Typically, non-Jews do not worry about categorizing their meals using "kosher," even though they can accurately describe things with that word. 


\section{Thick Explanations}

This approach to thick terms and concepts opens up room for a novel and serious objection to Cornell realism. Recall the putative moral explanations we entertained above:

(1) Honesty engenders trust.

(2) Kindness encourages friendship.

(3) Mother Teresa's goodness won her a Nobel Prize.

(4) People are starving unnecessarily because of the selfishness of others.

(5) Racial oppression caused political instability and social protest in apartheid South Africa.

(6) Hitler instigated and oversaw the deaths of millions of persons because he was morally depraved.

(7) Woodworth spent his time and energy arranging his own conveniences rather than organizing an effective search for the missing people because he was no damn good.

As you can see, some of these explanations - (1), (2), (4) and (5) - employ thick concepts, while the others - (3), (6) and (7) - employ thin concepts..$^{15}$

Remember that reductionists claim that the properties ascribed by evaluative vocabulary can be reduced to the properties ascribed by descriptive vocabulary. On the Pragmatic View, thick terms are part of our descriptive vocabulary. Thus, we can see that the descriptive property ascribed by the descriptive thick term "honesty" is what is appealed to in (1). But then it seems that (1) is no moral explanation. For one may accept that (1) is true (as we will here for the sake of argument) and accept that honesty is good (as we will here for the sake of argument), and yet fail to be committed to the existence of irreducible moral properties, since the goodness of honesty is not built into the meaning of "honesty."

It may be true that honesty is not reducible to lower-level properties. But reductive naturalists (e.g., Jackson, Railton, Harman) do not claim that moral properties reduce to the fundamental constituents of physics. That is, none of them endorse objectionable reductionism. For example, a hedonist who thinks that the good reduces to pleasure is not thereby endorsing objectionable reductionism - for pleasure is an irreducible psychological state. Thus, the fact that honesty is irreducible does not by itself entail that it is an irreducible moral property.

On the Pragmatic View, a relevant analog to (1) would be the claim that an explanation employing "neocortical column" can secure ontological status for psychological states. Although neocortical columns realize psychological states and are not reducible to entities describable using the vocabulary of physics, "neocortical column" is part of our neurophysiological vocabulary.

15 At least on first glance. I do not know what moral depravity is other than a condition of being very bad morally, but I will avoid this particular example in what follows. 
Thus, such explanations are not even candidates for supporting irreducible psychological states.

To see how this works, consider another, analogous case. At a concert in Miami in 1969, Jim Morrison was arrested and accused of exposing himself and simulating oral sex with the guitarist of The Doors while on stage (Hopkins 1995). Although some have disputed his guilt, assume the story is true. This suggests the following explanation:

(18) Jim Morrison's lewd behavior led to his arrest.

Let us assume that lewd behavior is not bad in any way because of its lewdness and that lewdness is an irreducible property of actions that can figure in our best explanations. On the Pragmatic View, (18) would then be true. Now let us switch one of our assumptions: All lewd acts are in fact very bad in virtue of transgressing social boundaries on sexual display. On the Pragmatic View, (18) would still be true. Since badness is not part of the meaning or truth-conditions of "lewd," simply endorsing (18) on either evaluative assumption cannot by itself commit one to nonreductive naturalism, and the same goes for other explanations employing thick terms.

One might think that the evaluative information conveyed through pragmatic mechanisms is still present in explanatory contexts such as (18) and might be important to the quality of the explanations. ${ }^{16}$ The problem is that the explanation needs to be explicit about this in order for it to have the kind of ontological significance necessary for Cornell realism. For example, due to shared background knowledge, if a neurosurgeon says to a fellow neurosurgeon "Joe has suffered a lesion to his fusiform gyrus," this will typically communicate that Joe's ability to recognize faces has been impaired. But talk about the fusiform gyrus all you want, you will not vindicate the ontological status of facial recognition, unless something like "facial recognition = activity in the fusiform gyrus" is true. But it is not. Machines can recognize faces with no gyri at all, and some argue that the fusiform gyrus does other things as well. To get ontological status for psychological phenomena, we need explanations that explicitly appeal to psychological phenomena (e.g., facial recognition) that cannot be adequately given without explicit appeal to such phenomena (e.g., through talk of gyri). (Indeed, if the explanation could be adequately given using purely neurological terms, then this would count against nonreductionism.) So in the same way, using descriptive vocabulary to talk about character traits cannot secure ontological status for evaluative properties, unless the properties ascribed by the descriptive vocabulary are identical to some of the properties ascribed by the evaluative vocabulary (i.e., unless reductionism is true). It does not matter that speakers associate positive or negative evaluations with the descriptive properties in question, just

16 I am grateful to an anonymous reviewer for pointing this out to me. 
like it does not matter that neurosurgeons associate psychological phenomena with certain brain regions.

To reinforce this point, consider another example. Imagine that the speaker from (17), later in the same conversation, utters the following:

(19) SeedCo's stock price is falling because fewer farmers are planting GMOs.

In the context, the hearer will know that the speaker takes this to be a good thing. However, this kind of explanation cannot support Cornell realism, for there is no evaluative language explicitly employed in the explanation. A reductionist can thus happily agree to the explanation and the evaluation. Indeed, the explanatory importance of morally significant phenomena can be accommodated by essentially any metaethical view, and even an error theorist could agree with (19). And notice that, in some contexts, a SeedCo executive could truthfully utter (19) in such a way that it conveyed a negative evaluation of the trend. As this example shows, because the evaluations are not part of the meaning of "GMO," the quality of the explanation is not dependent on the associated evaluation. And again, since "GMO," like "lewd," is not part of our evaluative vocabulary, explanations using "GMO" (or "lewd") cannot support Cornell realism.

The whole idea of reductive naturalism is that certain properties are Janus-faced. Sometimes they get cloaked in evaluative language and other times they get cloaked in descriptive language, but they remain one and the same property. Nonreductive naturalism must disagree. It requires explanations that a) employ evaluative language that ascribes evaluative properties that b) cannot be reduced to the descriptive properties ascribed by descriptive language. If the explanatory language is not inherently evaluative, then it cannot serve the role required of it. Thus, if thick terms are not inherently evaluative, explanations employing them cannot support nonreductive naturalism.

This highlights the way in which my argument is different from one that might be pursued by a separabilist who endorses Inherently Evaluative. If someone who endorsed that view were to argue that only the descriptive component of these evaluative terms is relevant to the putative moral explanations, then there would be significant work left to do to explain why the evaluative component is not relevant. This would be like showing that explanations that employ psychological predicates (e.g., "facial recognition") could not grant status for irreducible psychological phenomena. On the Pragmatic View, in contrast, explanations with thick terms and concepts are not even candidate moral explanations, since the thicks are not part of our evaluative vocabulary. They are part of our descriptive vocabulary, just as "GMO" is. Thus, my argument is analogous to discovering that "facial recognition" is a neurophysiological predicate. In that case, explanations employing "facial recognition" could not count against someone who thought that psychological facts reduce to neurophysiological facts. 
Notice that one of the strengths of this line of criticism comes from its ability to avoid glaring reductive mistakes as well as objectionable reductionism about properties in general. If the Pragmatic View is correct, then we can agree that honesty, oppression and lewdness are all irreducible properties that figure into the best explanations of various phenomena just like psychological states, DNA and so on. Unlike other objections to the explanations proffered by Cornell realists, this line of criticism allows us to agree that, e.g., (1), (2), (4) and (5) are all true. We can even grant Sturgeon et al. the truth of their considered moral beliefs and still maintain that these fail to be moral explanations, since only thick concepts (which are not inherently evaluative) have been employed.

Of course, given these concessions, it would be possible to turn (1), (2), (4) and (5) into moral explanations. We would simply need to adopt a reductive account according to which goodness, for example, is identified with some subset of the descriptive properties such that it is actually present in explanations like (1), (2), (4) and (5). If, for example, one endorsed a reductive account similar to Railton's (1986) or Harman's (1977), or the moral functionalism of Jackson and Pettit (1995; see also Jackson 1998), then even though the terms employed in (1), (2), (4) and (5) are not inherently evaluative, the properties those terms ascribe can be reductively identified with evaluative properties, and thus (1), (2), (4) and (5) turn out to be moral explanations after all. Of course, if this strategy were to be pursued, Cornell realism would cease to be a nonreductive variety of ethical naturalism, and thus would no longer be a unique position.

If this reductive strategy (or something like it) is not pursued by Cornell realists, then it seems they must concede that examples such as (1), (2), (4) and (5) really are not moral explanations at all. This would be a perilous move to make, however, since the explanations that employ thick concepts are the most plausible explanations that have been offered by advocates of Cornell realism. It is precisely this plausibility that makes it difficult to deny such explanations without making reductive mistakes or endorsing an objectionably reductionist position that forces one to also deny the existence of things like psychological states and DNA. This tension is very serious, and the upshot is this: If Väyrynen's Pragmatic View is correct, then Cornell realists cannot retain the most reasonable moral explanations they have offered without abandoning their position in favor of reductive naturalism.

Before moving on, another issue needs to be addressed. Admittedly, locutions of the form "a good $x$ " - such as "a good teacher" or "a good parent" - appear to be inherently evaluative in meaning and plausibly fall within the class of thick terms (in virtue of their descriptive content). One might, accordingly, think that explanations employing such phrases might be enough to do the trick, even if explanations employing paradigmatic thick 
concepts are given up on. For example, perhaps we can explain why Joan is well adjusted by appealing to the fact that she had good parents. ${ }^{17}$

This is a forceful argument. Nevertheless, I do not think that it is enough to support a view like Cornell realism. Among other things, it is worth noting that these kinds of descriptions can be applied to things that are not actually good. For example, one might rightly describe a person as a good assassin. ${ }^{18}$ They are stealthy, do not ask questions, have a high success rate, etc. Even if this is the case, assassins are generally not good.

This suggests that it might be promising to pursue an account of "a good $x$ " according to which the goodness in question has something to do with efficacy or relevant standards, rather than goodness in an unrestricted sense. Rawls (1971: 350-51), for example, offers such an account: "A is a good $\mathrm{X}$ if and only if $\mathrm{A}$ has the properties (to a higher degree than the average or standard $\mathrm{X}$ ) which it is rational to want in an $\mathrm{X}$, given what $\mathrm{X}$ 's are used for, or expected to do, and the like ..." If something along these lines is the best way to treat locutions of the form "a good $x$," then ideal-observer theories such as Railton's or Harman's are in a good position to handle explanations of this kind.

\section{Thin Explanations}

What about explanations employing thin concepts like GOOD and WRONG? If examples like (3), (6) and (7) are instances of best explanations, and there are reasons for thinking that goodness is an irreducible natural property, then the present challenge cannot be fatal to Cornell realism, since words like "good" and "wrong" are inherently evaluative, if any are. However, I think this approach is unpromising. In general, GOOD explanations are really no explanation at all, unless they are reductive.

The core problem is that it is simply not clear that explanations using thin evaluative terms can ground interesting counterfactual-supporting generalizations better than explanations with descriptively rich thick terms. Contrast the following two claims:

(3) Mother Teresa's goodness won her a Nobel Prize.

(3') Mother Teresa's selfless charity won her a Nobel Prize.

It seems to me that $\left(3^{\prime}\right)$ is an eminently better explanation than (3). There are many ways of being good, and it is for her extraordinary exemplification of the ways conveyed by ( $\left.3^{\prime}\right)$ that Mother Teresa was awarded the Nobel. Her goodness as such, on the other hand, does not tell us very much at all. On top of these thick terms, what explanatory good does calling her "good" do for us? Perhaps Jim is a good person, too! Knowing this offers no help in pre-

17 This example is inspired by a suggestion from an anonymous reviewer.

18 Väyrynen suggests this example (2013: 30. See also 155-56). 
dicting whether Jim will win the Nobel Prize. Even knowing that a person is very good is of no help. The Nobel committee looks for specific kinds of goodness when it makes its decisions, and it is from this knowledge that one can get some explanatory leverage. ${ }^{19}$

We can do even better. Consider (7).20 Suppose that someone who did not know a lot about Woodworth's character was told that he was no damn good. From this, what could be inferred? That he was a bank robber? That he was aggressive and frequently committed violent assaults? That he was rude in public? That he used his wealth to nefariously influence politics? That he was prone to instigate genocidal policies? Apparently none of these things follow in Sturgeon's example, for in fact Woodworth was just somewhat cowardly and selfish. And here is the point: Cowardice and selfishness are real properties that can explain the behavior in question much more informatively. They are ascribed by thick terms that are not inherently evaluative (cf. Sturgeon 2006: 250-51). Adding that Woodworth was no damn good does not make our explanation any better. In fact, it strips (7) of the explanatory power it would have had if Woodworth were instead described as cowardly and selfish. You can similarly watch yourself lose your explanatory grip if you try substituting in (irreducible) thin terms for the thick ones in (1), (2), (4) and (5), even though each thick term is plausibly construed as ascribing e.g., a good-making or wrong-making property. Notice that this situation is the reverse of the one with psychological explanations and neurological explanations - the increased explanatory power of psychological explanations over neurophysiological explanations is precisely what earned ontological rights for psychological states.

My arguments so far have neglected an important feature of explanation. As Brink (1989: 183-84) points out, even scientific hypotheses do not generate predictions in isolation. Perhaps when conjoined with some auxiliary premises GOOD explanations will fare better. To illustrate this very point, Brink (1989: 137-38) uses the following example. One might think that good people tend to keep their promises even at great personal cost. While this is predictively inert in isolation, one might join it with the hypothesis that Zenobia is a good person to predict that Zenobia will keep her promises at great personal cost.

I do not think this helps. Is it not also the case that trustworthy people tend to keep their promises? If that is true, why do we need to posit an extra irreducible property of goodness? Once again the attribution of irreducible

19 One might worry that, if there are many ways of being good, then we are right back at the multiple realizability considerations that favored nonreductionism in psychology. However, it may well be that the multiple realizability of goodness here is parasitic on the multiple realizability of its reduction base. After all, reductionists propose to reduce evaluative properties to irreducible, multiply realizable properties.

${ }^{20} \mathrm{I}$ take it that the "damn" in "no damn good" is not doing much more than emphasizing Woodworth's badness - akin to "no good at all." Although expressives like "damn" do appear to be inherently evaluative (Potts 2003), this does not affect the case. 
goodness actually impoverishes our explanation here, since it is plausible that not all good people are equally trustworthy. Unless we subscribe to an implausibly strong Socratic thesis about the unity of the virtues, attributing goodness to people - even particular degrees of goodness - does not help us very much for explanatory purposes. ${ }^{21}$

These examples illustrate that explanations that appeal to thin concepts are extremely flimsy - they can often be improved by jettisoning the thin concepts and substituting in more informative thick ones. In general, the thin explanations are comparatively imprecise and less relevant to the phenomena being explained when compared to thick explanations. In fact, it is reasonable to think that (nonreductive) GOOD explanations are really no explanation at all. But, if the Pragmatic View is correct, then thin moral explanations are the only ones that can support Cornell realism. This amounts to a substantial challenge to the view. Without a compelling story about thin moral explanations, the appeal of Cornell realism is significantly deflated.

One might worry that my arguments have been too dismissive of the value of the generality that GOOD explanations might offer. Perhaps goodness could be explanatorily relevant because it programs for the presence of other causally relevant properties, and thereby conveys modal information that would be lost without such explanations (Jackson and Pettit 1990). For example, maybe Woodworth would have exerted a malignant political influence if he were wealthy.

Even if there were GOOD explanations that were good for these reasons, it is less clear that these must favor nonreductive naturalism over reductive naturalism. Consider that, when reduction is appropriate, one can substitute co-referential terms (outside of intensional contexts) and maintain explanatory adequacy. For example, "She died because she stopped drinking water" and "She died because she stopped drinking $\mathrm{H}_{2} \mathrm{O}$ " appear to be explanatorily on par for those in possession of the relevant identity. ${ }^{22}$ While it might be difficult for reductive naturalists to offer the precision of explanations that employ thick terms without using those terms, it is not clear that they are unable to make headway with explanations that employ thin terms and concepts. For example, one might think that moral goodness leads to a flourishing life, but that appealing to specific kinds of moral goodness would fail to adequately capture this general fact. ${ }^{23}$ Although it would not be equivalent in

${ }^{21}$ Alex King has suggested to me that perhaps if a being were all-good, then this point may not hold. I am inclined to agree, but it seems that this fails to tell against the reductionist in favor of nonreductionism (see below).

22 Or consider Jackson and Pettit's (1990) classic example of a program explanation in which they account for the breaking of a glass container by appealing to the increased temperature of the water inside, rather than tracking the movements of individual molecules. Notice that the explanation would be just as good (for those aware of the relevant theory) if we switched out "temperature of the water" for "average kinetic energy of the water molecules," since these traits are identical.

${ }^{23} \mathrm{I}$ am grateful to an anonymous reviewer for pressing me on this point and offering this example. 
meaning, it is not clear that someone like Harman or Railton could not offer the same explanation in terms of the consequences of doing what one's ideally reasoning self would prescribe. Plausibly, following such prescriptions would lead to a flourishing life.

As I suggested, this kind of approach might not be effective for all of the explanations employing thick terms, such as greed and kindness. But if my earlier arguments are on track, then reductive naturalists need only worry about explanations that employ a handful of concepts - namely the thin ones (which are often analyzed in terms of one another). ${ }^{24}$ So even if there are good GOOD explanations, there is still more work to do to show that Cornell realism is preferable to reductive naturalism. Thus, even if my arguments against thin explanations are not definitive, the loss of thick explanations is a serious blow to the plausibility of Cornell realism.

\section{Conclusion}

Väyrynen's Pragmatic View of thick concepts essentially changes the debate between reductive and nonreductive moral naturalists by slimming down the class of evaluative language. I have argued that this tips the scales in favor of reductionism and against nonreductionism because it disqualifies the most plausible moral explanations from the debate, leaving available to Cornell realists only their least plausible examples.

I conclude that the viability of Cornell realism significantly depends upon the correct account of the semantics of thick concepts. In order for the view to be plausible, proponents need to offer a well-motivated account of thick concepts that can compete with Väyrynen's Pragmatic View, or show that thin moral explanations are sufficient to earn ontological rights for irreducible moral properties. It remains to be seen whether either can be done. 25

Brendan Cline

University at Buffalo, SUNY

Department of Philosophy

bcline@buffalo.edu

${ }^{24}$ E.g., Scanlon (1998). This strategy informs the approach to reductionism that Schroeder (2007) pursues, although he operates with a somewhat different understanding of reductionism than has been standard in metaethical debates. See also Schroeder (2005).

25 I am grateful to Ken Shockley and three anonymous reviewers for valuable comments on earlier drafts of this paper. I am also grateful for helpful discussion with Ariane Nomikos and an audience at the University at Buffalo. 


\section{References}

Bedke, M. S. (2014) "Review of The Lewd, the Rude and the Nasty," Notre Dame Philosophical Reviews, April 30, ndpr.nd.edu/news/ 47974-the-lewd-the-rude-and-the-nasty.

Blackburn, S. (1993) Essays in Quasi-Realism, New York: Oxford University Press. (1992) "Through Thick and Thin," Aristotelian Society Supplementary Volume 66: 285-99. (1984) Spreading the Word: Groundings in the Philosophy of Language, Oxford: Oxford University Press.

Boyd, R. (2003a) "Finite Beings, Finite Goods: The Semantics, Metaphysics and Ethics of Naturalist Consequentialism, Part I," Philosophy and Phenomenological Research 66(3): 50553. (2003b) "Finite Beings, Finite Goods: The Semantics, Metaphysics and Ethics of Naturalist Consequentialism, Part II," Philosophy and Phenomenological Research 67(1): 24-47. (1988) "How to Be a Moral Realist," in G. Sayre-McCord, ed., Essays on Moral Realism, Ithaca, NY: Cornell University Press, pp. 181-228.

Brink, D. O. (1989) Moral Realism and the Foundations of Ethics, New York: Cambridge University Press.

Elstein, D. and Hurka, T. (2009) "From Thin to Thick: Two Moral Reductionist Plans," Canadian Journal of Philosophy 39: 515-35.

Fodor, J. (1974) "Special Sciences (or: The Disunity of Science as a Working Hypothesis)," Synthese 28: 97-115.

Gibbard, A. (1992) “Thick Concepts and Warrant for Feelings," Aristotelian Society Supplementary Volume 66: 267-85.

(1990) Wise Choices, Apt Feelings: A Theory of Normative Judgment, Cambridge, Mass.: Harvard University Press.

Harman, G. (1986) "Moral Explanations of Natural Facts - Can Moral Claims Be Tested Against Moral Reality?" Southern Journal of Philosophy 24(S1): 57-68. (1977) The Nature of Morality: An Introduction to Ethics, New York: Oxford University Press.

Hopkins, J. (1995) "The Lizard King: The Essential Jim Morrison," New York: Fireside.

Jackson, F. (1998) From Metaphysics to Ethics: A Defense of Conceptual Analysis, Oxford: Oxford University Press.

Jackson, F. and Pettit, P. (1996) "Moral Functionalism, Supervenience and Reductionism," The Philosophical Quarterly 46(182): 82-86. (1995) "Moral Functionalism and Moral Motivation," The Philosophical Quarterly 45(178): 20-40. (1990) "Program Explanation: A General Perspective," Analysis 50(2): 107-17.

Joyce, R. (2001) The Myth of Morality, Cambridge: Cambridge University Press.

Kirchin, S. (2010) “The Shapelessness Hypothesis,” Philosophers' Imprint 10(4): 1-28.

Korsgaard, C. M. (1996) The Sources of Normativity, Cambridge: Cambridge University Press.

Kyle, B. G. (2013) “How Are Thick Terms Evaluative?” Philosophers' Imprint 13(1): 1-20.

Leiter, B. (2001) "Moral Facts and Best Explanations," Social Philosophy and Policy 18(2): 79101.

Mackie, J. L. (1977) Ethics: Inventing Right and Wrong, New York: Penguin.

Majors, B. (2007) "Moral Explanation," Philosophy Compass 2(1): 1-15. (2003) "Moral Explanation and the Special Sciences," Philosophical Studies 113(2): 121 52.

Miller, A. (2013) Contemporary Metaethics: An Introduction, second edition, Malden, Mass.: Polity Press. (2009) "Moral Realism and Program Explanation: A Very Short Symposium 1: Reply to Nelson," Australasian Journal of Philosophy 87(2): 337-41.

Nelson, M. (2006) "Moral Realism and Program Explanation," Australasian Journal of Philosophy 84(3): 417-28. 
Potts, C. (2003) "Expressive Content as Conventional Implicature," Proceedings of the North East Linguistic Society 33: 303-22.

Quinn, W. S. (1986) "Truth and Explanation in Ethics," Ethics 96(3): 524-44.

Railton, P. (1986) "Moral Realism," The Philosophical Review 95(2): 163-207.

Rawls, J. (1971) A Theory of Justice, Cambridge, Mass.: Harvard University Press.

Roberts, D. (2011) "Shapelessness and the Thick," Ethics 121(3): 489-520.

Sayre-McCord, G. (1988) "Moral Theory and Explanatory Impotence," in G. Sayre-McCord, ed., Essays on Moral Realism, Ithaca, NY: Cornell University Press, pp. 256-81.

Scanlon, T. M. (1998) What We Owe to Each Other, Cambridge, Mass.: Harvard University Press.

Schroeder, M. (2007) Slaves of the Passions, New York: Oxford University Press. (2005) 'Realism and Reduction: The Quest for Robustness," Philosophers' Imprint 5(1): $1-18$.

Simons, M., Tonhauser, J., Beaver, D. and Roberts, C. (2010) "What Projects and Why," in N. Li and D. Lutz, eds., Proceedings of SALT (Semantics and Linguistic Theory) 20, Ithaca, NY: CLC Publications: 309-27.

Sinclair, N. (2011) “The Explanationist Argument for Moral Realism," Canadian Journal of Philosophy 41(1): 1-24.

Sturgeon, N. (2006) "Moral Explanations Defended," in J. Dreier, ed., Contemporary Debates in Moral Theory, Cambridge, Mass.: Blackwell: 241-62.

(1998) "Review: Thomson Against Moral Explanations," Philosophy and Phenomenological Research 58(1): 199-206. (1988) "Moral Explanations," in G. Sayre-McCord, ed., Essays on Moral Realism, Ithaca, NY: Cornell University Press, pp. 229-55.

(1986) "Harman on Moral Explanations of Natural Facts," Southern Journal of Philosophy 24(S1): 69-79.

Thomson, J. J. (1996) "Epistemological Arguments for Moral Skepticism," in G. Harman and J. J. Thomson, Moral Relativism and Moral Objectivity," Cambridge, Mass.: Blackwell, pp. 69-94.

Väyrynen, P. (2013) The Lewd, the Rude and the Nasty: A Study of Thick Concepts in Ethics, New York: Oxford University Press.

(2012) “Thick Concepts: Where's Evaluation?” in R. Shafer-Landau, ed., Oxford Studies in Metaethics, Vol. 7, Oxford: Oxford University Press, pp. 235-70.

(2009) "Objectionable Thick Concepts in Denials," Philosophical Perspectives 23(1): 43969.

Williams, B. (1985) Ethics and the Limits of Philosophy, New York: Oxford University Press. 